\title{
Some Aspects of Technology in Teaching English to English Language Learners
}

\author{
Owen G Mordaunt \\ Matthew McGuire \\ Department of English \\ University of Nebraska at Omaha \\ Omaha NE, USA
}

\begin{abstract}
The New Literacy Studies, sometimes called NLS, refers to a body of work that started in the 1980s and applies to how technology and literacy impact our lives, identities and social affiliations. NLS developed from linguistics, history, anthropology, rhetoric and composition studies, cultural psychology, education, and other fields of study. In this paper, specific reference is made to technology use in a 1300-level English class for Language Learners in the Intensive Language Program at the University of Nebraska at Omaha. The paper also makes a few comments about the importance of technology in teaching English in contexts other than USA classroom.
\end{abstract}

Keywords: New Literacy Studies, technology, teaching English, language learners, Intensive Language Program

\section{Introduction}

The language that has developed through the widespread use of social media is markedly different from the language that has traditionally been prescribed in schools. However, it has become as much a part of the English that English Language Learners (ELLs) are coming into contact with, in addition to traditional literature. Some research suggests that this is entirely appropriate: that understanding the means of expression in one context might lend itself to an understanding of expression in another context. Appropriate or not, ELLs are interacting with English through technology more and more. New Literacy Studies, or NLS, suggests that there is validity in every form of expression as long it is successful. Observations of ESL classrooms indicate that technology is becoming invaluable, and the use of technology by English teachers in non-English speaking communities suggests the impact of technology in teaching English will only increase.

\section{New Literacy Studies}

According to Compton-Lilly, New Literacy Studies (NLS) "refers to how literacy practices are linked to peoples' lives, identities, and social affiliations" (Compton-Lilly, 2009, p. 88).In addition, NLS "requires language and literacy to be studied as they occur naturally in social life, [and take] account of the context" (Street, 1997, p. 47). In terms of practical application to students' lives, NLS acknowledges the "significance of children's interactions with technological texts and views these interactions as meaningful and purposeful" (Compton-Lilly, 2009, p. 89). In the past, there has been a distinction made between the study of different modes of communication. There is, however, an idea in NLS that "children bring to school language capacities which must be built upon, if the induction into the standard written form of the language... is tobe successfully accomplished" (Stephens, 2000, p. 21).

In NLS it is important to understand literacy as being a broader issue than what takes place in the classroom. Street discusses the contrasting ideas of what, exactly, constitute literary practices:"Whilst literacy practices may traditionally refer to classroom behaviors, literacy practices allow us to adopt a broader and more culturally relative perspective and thereby to see and value varieties of literacy practices that we might otherwise miss and that would certainly remain marginalized" (Street, 1997 p. 50). This idea easily encompasses the non-prescriptive usages found in exchanges on social media platforms. NLS scholars acknowledge the validity of such language as is used so long as it is effective. While it may take some readjustment for traditional instructors, this means that any interaction that students have, either in the prescribed forms of the classroom, or the abbreviated language of social media, is going to help them to connect with expression in English. According to Leu, et al (2013), the new literacies of online research and comprehension involve problem-based inquiry, using information on the internet. This includes using skills, strategies, dispositions and social practices that occur as we read online information, and this centers around reading (a) "to identify important questions," (b) "to locate information," (c) "to evaluate information critically," (d) "to synthesize information," and (e) "to communicate information" (p. 1164). 


\section{Observations of Technology Use}

This theory is borne out by observations that were made with very few preconceived ideas about the technical requirements or technological possibilities for second language instruction that highlight the importance of technology in the classroom. These are observations of ten hours of classroom time for a low level (1300) English for speakers of other languages classroom, in this case five Saudi students and one Chinese student.

The 1300 class is called "Reading \& Writing: Foundations." It is a two-month session within a one-year intensive language program at the University of Nebraska at Omaha. According to the description on the University website, 1300 is the most basic foundational course that students can take. The course is designed to "build basic familiarity with the sounds and shapes of the English alphabet. . . through careful guidance on writing letters, words, phrases, and simple sentences. . . . Students read level-appropriate texts . . . Grammar covers parts of speech, singular and plural nouns, proper word order for yes/no question construction, and sentence fragments" (ILUNO webpage, 2015). The course and the program fall under the category of "sheltered" language instruction, which is "an approach where ELLs are grouped together so that they do not have to try to compete with native English speakers" (Horwitz, 2013, p. 6). This is also a type of immersion language learning, as the students are living in an English speaking community with language support from the school. In total the students are in class twenty-one hours per week working specifically on learning English without distraction by native speakers.

Physically, the classroom design was uncomplicated and open. One podium with a computer at the head of the room faced the rest of the class, with a white projection screen behind it. The students sat in twos or threes at long tables facing the podium.

One practice continuously observed during these classes is the processing and reprocessing of information into new forms. This is true for teachers; who have to try to adjust to different styles of learning in their students, but for students learning English as well. Over the course of observed classes students had to process information in a number of ways.

a. They had to read passages and answer questions based on vocabulary as well as content.

b. They had to familiarize themselves with passages and read them aloud in class.

c. They had to draw pictures on the board of representations of vocabulary words.

d. They had to type out notes of a lecture, to be proofed and handed in to demonstrate their mastery of spelling, grammar, and ability to recognize key ideas when spoken aloud.

e. They had to match pictures with the vocabulary words they depicted.

In one exercise each student had to act out a verb, while the rest of the class tried to guess what it was. The instructor pulled images from the internet and projected them on a screen and then had the students identify the actions that could be taking place in different tenses. In a wide variety of ways, the students were given the opportunity to connect spoken words with actions with images with written expression. These mixed approaches allowed the students to develop a more complex understanding of the building blocks of the English language. It also allowed the instructor more ways to identify any disconnects between her instruction and the students' understanding.

This approach can be extremely beneficial in teaching English in a non-English speaking community. If nothing else, the variety of ways that students can become acquainted with various aspects of English could help bridge the communication gap for an instructor who does not share a language with the class. In approaching vocabulary and sounds and grammar over and over again from so many different angles, the students have that many opportunities to understand what the teacher is trying to convey.

The idea of approaching the same information from different angles leads into another theme observed from the very first class meeting. It is important not to underestimate the importance of patience on the part of both the instructor and the students in the process of learning a new language. So many times in every class the instructor had to explain an idea or a question over and over again using different words or images or even pantomime.

In the context of the ELL classroom, pantomime falls under a method called Total Physical Response, or TPR. The importance of TPR teaching methodology cannot be overstated in the second language classroom. It involves listening comprehension on the part of students-listening to commands given by the teacher in the target language and modeling the actions required by the commands. Students are required to follow the commands and act them out using the whole "bodies."Not only does the instructor have to be patient enough to go through the process, but the students have to sit through it and wait for one of the restatements to make sense.

One important way that information is reprocessed is through technology. During the class times observed, both the students and the instructor used technology almost constantly. Students were not allowed to use their phones for personal issues during class, but quite often used them for translation applications. 
A search of the Google play store for the word "translator" comes up with hundreds of these applications, most of them free, which is anecdotal evidence that the use of translator applications is common. The students also required access to computers to work on typing in English. It is not clear how important access to the translation applications was, though they were used quite often. The computers were vital, however, because learning typing is actually part of the 1300 class, as previously mentioned. To use the computers, the class had to go to the public computers in the Criss Library at the University of Nebraska at Omaha. In the classroom itself, there is only one computer, as mentioned, used by the teacher. This is connected to a screen on the wall as large as a traditional whiteboard. In a classroom of the size observed, the screen was easily visible to all occupants. The instructor used this screen to show pages of the textbooks and written information. The screen was also every effective for displaying images taken from the internet to help with explanations or exercises. One example of the use of this technology for aiding in second language teaching was to pull an image from the internet and show it on the screen. The students would then describe the actions that could be taking place within the image using the verbs and verb forms they were learning. Between the technology used by the students and the technology used by the instructor, it is clear that the ILUNO program is taking steps to continually integrate technology into the structure of their program.

\section{Technology in Education}

The importance of technology in teaching English is not restricted to American classrooms. Research done all over the world has shown that "in order to develop critical literacy skills for foreign language learners, computer-based technologies are more useful than the conventional method of teaching" (Levine et al., 2000 as cited in Saqlain \& Mahmood 2013, p. 107).

One study by Christoph A. Hafner experimented with the using technology, and with communicating through multimodal texts. This impacts second language teachers and learners, "who are increasingly involved in the consumption and production of multimodal texts" (Hafner 2013, p. 660). Moving to understand and take advantage of that interaction, his article explores the pedagogical value of expression in multiple modalities for L2 students in a discipline-specific English course at a Hong Kong university. The students had to report the results of an experiment in two modalities: a creative YouTube video and an academic lab report. The work draws on theory from NLS suggesting literacy is "socially situated," meaning that "reading and writing are accomplished in service of social goals in particular social contexts" (Hafner 2013, p. 657). People express themselves differently in a post on social media than they do in a lab report, as the two represent distinct discourse communities and demand different levels of formality. In the context of language learning, it is important to experience the different contexts to learn how to communicate within them. Learners are able to pick up the discourse, which amounts to an identity within a specialized discipline. Language learners develop an authorial, or discoursal identity through working in a new discourse community. Academic discourse is traditionally impersonal and restrained, so learners may find themselves less comfortable expressing themselves in voice they have not yet fully developed. By working with the material in a modality that might feel more natural, like social media, Hafner hoped that the students would be better equipped to express the same material later in a modality that can be more intimidatingly academic. The experiment was a success by the measures Hafner employed, which supports the proposition that literacy in one context can work to improve literacy in another.

One of the data sources Hafnerused was online blog posts made by students over the course of the experiment. The importance of online communication, either through blogging or facebook, is supported by other research. However, the impact of traditional interactions should not be understated for learning specific aspects like the grammar of a new language. According to Saqlain \& Mahmood (2013), "The research is very clear about the importance of electronic discussion. Warschaur (1996) found that the students had greater equality of participation in the electronic participation .... students could express themselves freely, comfortably, and creatively during electronic discussion" (p. 107). This fact should be of special interest to teachers who are trying to get students to engage with them in the classroom.

\section{Conclusion}

Street argues that "the fears and desires associated with dialogic and social interpretations of language and literacy have been largely associated with a reactionary and self-interested elite" (1997, p. 52). It could be that the disparagement of the new language of "lol," and however else people express themselves on social media, is nothing more than this. It is fairly certain however, that technology, and the language that can be associated with it, will become more firmly integrated into education in the future. In the observed language learning classes in UNO's ILUNO program it is already an invaluable asset to both students and instructors. Technology and its applications for education and communication are certainly not going to stop advancing, and New Literacy Studies validate the modes of expression that spring from their use. 
Integrating technology into traditionally structured language learning programs has already proven to be measurably effective in many non-English speaking communities, including the Universities of Saudi Arabia. For English teachers, technology is an extremely effective tool to engage with students and engage students with a wider, English speaking world.

\section{References}

Compton-Lilly, C. F. (2009). What can new literacy studies offer to the teaching of struggling readers? The Reading Teacher, 63(1), 88-90.

Hafner, C. A. (2013). Embedding digital literacies in English language teaching: Students' digital video projects as multimodal ensembles. TESOL Quarterly 48(4), $\quad 655-685$.

Horwitz, E. K. (2013). Becoming a Language Teacher: A practical guide to second language learning and teaching (2nded.). Boston, M.A.: Pearson Education. ILUNO Intensive English.(n.d.).Retrieved April 10, 2015.

Leu, D.T., Kinzer, C.K.,Coiro, J., Castek, J.\& Henry, L.A. (2013). New Literacies: a Dual level theory of the changing nature of literacy, instruction, and assessment. In Alvermann, D.E., Unrau, N.J.\& Ruddell, R. B. (Eds).Theoretical Models and Processes of Reading (6th. Ed). International Reading Association. Available at http://www.reading.org/Libraries/books/IRA-710-chapter 42 pdf.

Saqlain, N. \& Mahmood, Z. (2013). English language instructors' perceptions about technology-based language learning at Northern Border University in Saudi Arabia. The Turkish Online Journal of Educational Technology, 12(2), 106-110.

Stephens, K. (2000). A critical discussion of the "New Literacy Studies."British Journal of Educational Studies, 48(1), 10-23.

Street, B. (1997). The implications of the 'New Literacy Studies' for literacy education. English in Education, 31(3), 45-59. 